\title{
Study of Surface Metallization of Polyimide Film and Interfacial Characterization
}

\author{
Pei-Yu Wu, Ching-Hsuan Lin and Chih-Ming Chen * \\ Department of Chemical Engineering, National Chung Hsing University, Taichung 402, Taiwan; \\ pennyabc3@gmail.com (P.-Y.W.); linch@dragon.nchu.edu.tw (C.-H.L.) \\ * Correspondence: chencm@nchu.edu.tw; Tel.: +886-4-2285-9458
}

Academic Editor: Håkan Hallberg

Received: 22 March 2017; Accepted: 20 May 2017; Published: 25 May 2017

\begin{abstract}
Nickel (Ni) metallization of polyimide (PI) was performed using a solution-based process including imide-ring opening reactions, the implanting of $\mathrm{Ni}$ ions, the reduction of catalytic $\mathrm{Ni}$ nanoparticles, and the electroless deposition of a $\mathrm{Ni}$ film. The start-up imide-ring opening reaction plays a crucial role in activating inert PI for subsequent Ni implanting and deposition. A basic treatment of potassium hydroxide $(\mathrm{KOH})$ is commonly used in the imide-ring opening reaction where a poly(amic acid) (PAA) layer forms on the PI surface. In this study, we report that the $\mathrm{KOH}$ concentration significantly affects the implanting, reduction, and deposition behavior of $\mathrm{Ni}$. A uniform Ni layer can be grown on a PI film with full coverage through electroless deposition with a $\mathrm{KOH}$ concentration of $0.5 \mathrm{M}$ and higher. However, excessive imide-ring opening reactions caused by $5 \mathrm{M} \mathrm{KOH}$ treatment resulted in the formation of a thick PAA layer embedded with an uneven distribution of Ni nanoparticles. This composite layer (PAA + Ni) causes wastage of the Ni catalyst and degradation of peel strength of the Ni layer on PI.
\end{abstract}

Keywords: metallization; $\mathrm{Ni}$; polyimide; interfacial microstructure; nanoparticle

\section{Introduction}

Recently, wearable and portable technologies have attracted considerable attention because multiple functions such as communication, internet, sensor, navigation, and media, can be integrated in a small and light-weight device [1-9]. The rapid development of wearable and portable devices has driven the microelectronic industries to develop new technologies to meet the demands of scale miniaturization and multi-functionality. The flexible printed circuit board (FPCB) plays an important role in the development of wearable and portable devices due to its high flexibility in reducing packaging volume. Polyimide (PI) is a superior material as a substrate of FPCB and has many advantages such as light-weight, high thermal stability, and good anti-corrosion properties [1,3,6,8-19]. PI also has a high potential in automotive applications [1] as it has a higher glass transition temperature $\left(T_{\mathrm{g}}\right)$ at $280-290{ }^{\circ} \mathrm{C}$, which is more sustainable in a high-temperature operational environment. Interestingly, pyromellitic dianhydride-4,4-oxydianiline (PMDA-ODA) PI film shows good sensing characteristics in the detection of ammonia vapors, which has opened a smart application direction for PI [20].

PI is non-conductive, so metallization is necessary to offer electrical transmission routes for separate components packaged on its surface. A common and mature metallization method is copper clad laminate (CCL), which is performed by laminating an electro-deposited (or rolled annealed) $\mathrm{Cu}$ foil on a PI film with an intermediate adhesive layer [1,9]. The laminated $\mathrm{Cu}$ foil is usually $18-35 \mu \mathrm{m}$ thick to sustain sufficient mechanical strength; however, this thickness issue may make CCL technology unsuitable for fine-pitched wearable and portable devices. An alternative method is to grow a thin metallic layer directly on the PI using sputtering [21-23] or electrochemical 
deposition [6,13,24-28]. Sputtering can produce a dense and uniform metallic layer with good adhesion on PI, but the high-vacuum operational environment makes cost-down difficult to achieve. In contrast, solution-based electrochemical deposition is a cost-effective method. Prior to electrochemical deposition, the inert PI surface needs to be activated/modified by a base treatment of potassium hydroxide $(\mathrm{KOH})$, ion exchange, and catalyst reduction $[4,8,10,27-34]$. Pd is a traditional catalyst due to its superior catalytic activity, but is expensive. Therefore, nano-sized $\mathrm{Ni}$ is proposed as an alternative catalyst $[30,31]$. After forming a catalytic nanoparticle layer on the PI surface, a thin metallic layer-usually a nickel (Ni) diffusion barrier-is grown by electroless deposition [2,18,24,30,31,35]. The thickness of the Ni plated layer usually ranges from hundreds of nanometers to a few micrometers to be an effective diffusion barrier. Finally, a Cu layer is electroplated on the electroless Ni layer to accomplish the metallization of polyimide [2].

The base treatment of $\mathrm{KOH}$ is a ring-opening reaction which can implant the $\mathrm{K}^{+}$ions into the uppermost sublayer of PI to form a potassium salt poly (amic acid) (PAA) layer [1,4,8,10,32]. The PAA layer plays an important role for the subsequent metallization process. In this study, the effect of the base treatment of $\mathrm{KOH}$ with various concentrations on the property of PAA was systematically investigated. Detailed microstructural characterizations of PAA including $\mathrm{K}^{+}$ion implanting, $\mathrm{Ni}$ nanoparticle (catalyst) formation, and electroless deposition of $\mathrm{Ni}$, were performed using transmission electron microscopy (TEM).

\section{Experimental Procedures}

\subsection{Materials}

Commercial Kapton-HN PI film (DuPont, Wilmington, DE, USA) was purchased and used without modification. The chemicals used for PI metallization were also purchased and used without any modification, including $\mathrm{KOH}$ (Sigma-Aldrich, St. Louis, $\mathrm{MI}, \mathrm{USA}$ ), $\mathrm{NiCl}_{2}$ (AlliedSignal, Morristown, $\mathrm{NJ}, \mathrm{USA}), \mathrm{NaBH}_{4}$ (Sigma-Aldrich, St. Louis, MI, USA), and Ni electroless plating solution (9026M, OM Group, Cleveland, OH, USA).

\subsection{Metallization Process of PI}

PI film was used as the substrate and surface-metallized following the procedure shown in Figure 1. First, the PI film was rinsed using de-ionized water and immersed in an ultrasonic ethanol solution for $30 \mathrm{~min}$. The as-cleaned PI film was then immersed in a $\mathrm{KOH}$ solution at room temperature for 5-15 min to form a PAA layer on the PI surface. The concentrations of the $\mathrm{KOH}$ solution were 0.1, $0.5,1.0$, and $5.0 \mathrm{M}$. After the base treatment of $\mathrm{KOH}$, the modified PI film was immersed in a $0.1 \mathrm{M}$ $\mathrm{NiCl}_{2}$ solution at $50{ }^{\circ} \mathrm{C}$ for $5 \mathrm{~min}$ for the ion exchange reaction. The implanted $\mathrm{K}^{+}$ions in the PAA layer were exchanged by the $\mathrm{Ni}$ ions released from the $\mathrm{NiCl}_{2}$ solution. The $\mathrm{Ni}$ ions were subsequently reduced to form catalytic Ni nanoparticles using $\mathrm{NaBH}_{4}(0.1 \mathrm{M})$ as the reductant. The reduction reaction was performed at room temperature for $3 \mathrm{~min}$. After reduction, the PI film was immersed in a commercial Ni plating solution so a thin Ni layer on the PI film using electroless deposition could be grown. The Ni plating solution contained sodium hypophosphite $(28 \mathrm{~g} / \mathrm{L})$ as the reductant and the electroless deposition was performed at $85^{\circ} \mathrm{C}$ for $1 \mathrm{~min}$.

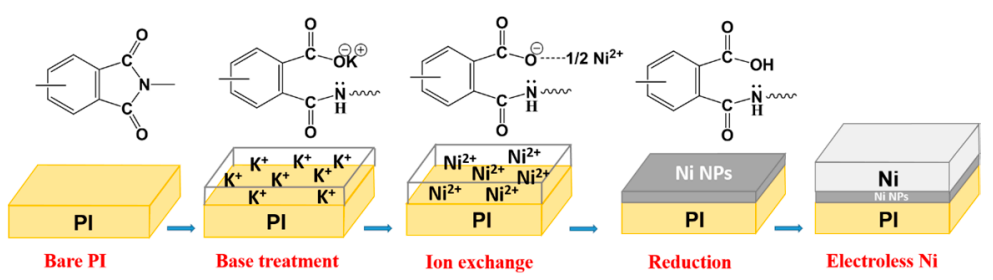

Figure 1. Schematic of the metallization process of Ni on a polyimide (PI) film. 


\subsection{Characterization}

\subsubsection{Imide-Ring Opening Reaction and Contact Angle}

After base treatment with $\mathrm{KOH}$, the ring-opening condition was examined using an attenuated total reflection-Fourier transform infrared spectroscope (ATR-FTIR, RX I, Perkin-Elmer, Norwalk, CT, USA). The contact angle of the PI film before and after $\mathrm{KOH}$ treatment was measured by a contact angle instrument using water drop.

\subsubsection{Surface and Cross-Sectional Microstructures of Ni-Metallized PI Film}

After the metallization process, the surface morphology of the PI film was observed using a digital camera to understand metallization uniformity. Next, the metallized PI film was cross-sectioned using a focused ion beam (FIB, XVision 200TBS, Seiko, Chiba, Japan). The exposed interior microstructure of the Ni/PI interface was observed using a transmission electron microscopy (TEM, FEI Tecnai, Hillsboro, OR, USA). The elemental composition was determined using energy dispersive X-ray spectrometer (EDX).

\subsubsection{Peel Strength Test}

A universal pull-off tester (ST-RX N001, MOGRL Technology, Taiwan) was used to measure the adhesion strength between the metallization layer and the PI film. To perform the peel test, a Cu layer was grown on the Ni-coated PI film using electroplating in a Haring cell containing a typical $\mathrm{Cu}$ plating solution $\left(\mathrm{CuSO}_{4}+\mathrm{H}_{2} \mathrm{SO}_{4}\right)$. The plating temperature, current density, and time were $28{ }^{\circ} \mathrm{C}$, $10 \mathrm{ASF}$, and $2 \mathrm{~h}$, respectively. The pull-off speed was set at $51 \mathrm{~mm} / \mathrm{min}$.

\section{Results and Discussion}

\subsection{ATR-FTIR and Contact Angle Analyses of KOH-Treated PI Films}

The base treatment of $\mathrm{KOH}$ is a ring-opening reaction during which the hydroxyl group attacks the symmetric imide rings of PI and breaks the $-\mathrm{C}-\mathrm{N}-\mathrm{C}-$ bonds. The extent of ring-opening can be determined by ATR-FTIR analysis [30]. Figure 2 shows the transmittance spectra of the PI films before (bare) and after base treatment of $\mathrm{KOH}$. Two characteristic transmittance peaks were taken into consideration. One was the characteristic peak at $1500 \mathrm{~cm}^{-1}$ for the $\mathrm{C}=\mathrm{C}$ bond of the benzene ring. As the molecular structure of the benzene ring hardly changes under attack with $\mathrm{KOH}$, the characteristic peak at $1500 \mathrm{~cm}^{-1}$ can be used as a reference. The second peak was the characteristic peak at $1720 \mathrm{~cm}^{-1}$ for the symmetric stretching $\mathrm{C}=\mathrm{O}$ bond of the imide ring. The base treatment of $\mathrm{KOH}$ resulted in the cleavage of the imide ring, thus the intensity of the characteristic peak at $1720 \mathrm{~cm}^{-1}$ decreased. By comparing the relative intensity changes of the characteristic peak at $1720 \mathrm{~cm}^{-1}$ (imide ring) and that at $1500 \mathrm{~cm}^{-1}$ (benzene ring), the ring-opening extent of the imide ring can be determined. As shown in Table 1, the ratio of absorbance at $1720 \mathrm{~cm}^{-1}$ to that at $1500 \mathrm{~cm}^{-1}\left(\mathrm{~A}_{1720} / \mathrm{A}_{1500}\right)$ for bare PI film was assumed to be $100 \%$ imide content on the PI surface. It was found that the ratio of $\mathrm{A}_{1720} / \mathrm{A}_{1500}$ decreased with increases in $\mathrm{KOH}$ concentration. After the base treatment of $\mathrm{KOH}(5.0 \mathrm{M})$, the imide content was $8.22 \%$, meaning that $91.78 \%$ of imide rings on the PI surface were cleaved. The cleavage of the imide rings generates carboxylic acids and amides (Figure 1), which makes the modified PI film more wettable as indicated by the decreased contact angle with increased $\mathrm{KOH}$ concentration (Table 1).

\subsection{Surface Metallization of PI Film}

Figure 3 shows the digital images of the surface morphologies of PI after Ni metallization. It was found that $\mathrm{KOH}$ concentration was crucial for metallization uniformity. At a lower $\mathrm{KOH}$ concentration (0.1 M), although the PI film could be metallized by Ni, metallization uniformity was poor. The electroless deposited Ni layer was easily peeled off when the as-metallized PI films were rinsed with 
water, or blown by air gun. Metallization uniformity became better when the $\mathrm{KOH}$ concentration was increased to $0.5 \mathrm{M}$ and higher.

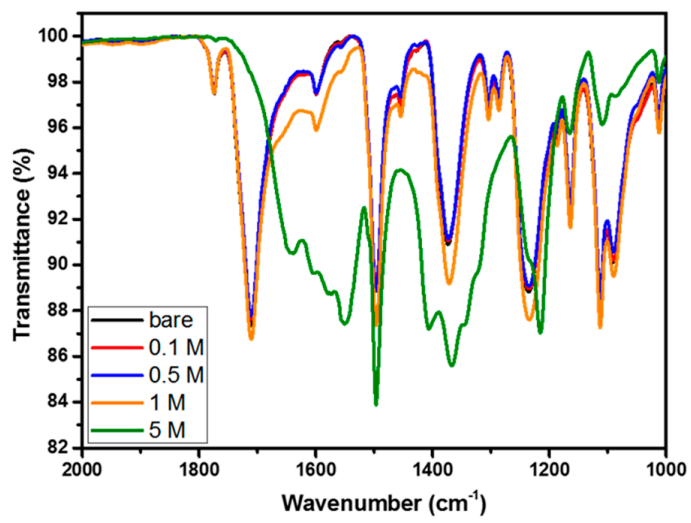

Figure 2. Transmittance spectra of the PI films before and after base treatment of $\mathrm{KOH}$.

Table 1. Dependence of optical transmittance/absorbance, relative surface imide content, and contact angle of modified PI films on potassium hydroxide $(\mathrm{KOH})$ concentrations.

\begin{tabular}{|c|c|c|c|c|c|c|c|}
\hline \multirow{2}{*}{ KOH (M) } & \multicolumn{2}{|c|}{ Transmittance (\%) } & \multicolumn{2}{|c|}{ Transmittance/Absorbance } & \multirow{2}{*}{$A_{1720} / A_{1500}$} & \multirow{2}{*}{$\begin{array}{l}\text { Relative Surface } \\
\text { Imide Content }(\%)\end{array}$} & \multirow{2}{*}{$\begin{array}{l}\text { Contact } \\
\left.\text { Angle ( }{ }^{\circ}\right)\end{array}$} \\
\hline & $1720 \mathrm{~cm}^{-1}$ & $1500 \mathrm{~cm}^{-1}$ & $1720 \mathrm{~cm}^{-1}$ & $1500 \mathrm{~cm}^{-1}$ & & & \\
\hline 0 & 87.35 & 88.85 & $0.8735 / 0.05$ & $0.8885 / 0.0513$ & 1.144 & 100 & 80.06 \\
\hline 0.1 & 87.63 & 89.04 & $0.8763 / 0.05$ & $0.8904 / 0.0504$ & 1.137 & 99.39 & 55.55 \\
\hline 0.5 & 87.75 & 88.89 & $0.8775 / 0.05$ & $0.8889 / 0.0511$ & 1.112 & 97.20 & 28.81 \\
\hline 1 & 86.75 & 87.36 & $0.8675 / 0.06$ & $0.8736 / 0.0587$ & 1.051 & 91.87 & 22.03 \\
\hline 5 & 98.35 & 83.88 & $0.9835 / 0.00$ & $0.8388 / 0.0763$ & 0.094 & 8.22 & 20.74 \\
\hline
\end{tabular}

\begin{tabular}{|c|c|c|c|}
\hline KOH concentration & $5 \mathrm{~min}$ & $10 \mathrm{~min}$ & $15 \mathrm{~min}$ \\
\hline $0.1 \mathrm{M}$ & & & \\
\hline & & & \\
\hline $0.5 \mathrm{M}$ & & & \\
\hline $1 \mathrm{M}$ & & & \\
\hline & & & \\
\hline & & & \\
\hline & & & \\
\hline & & & \\
\hline & & & \\
\hline & & & \\
\hline
\end{tabular}

Figure 3. Digital images of the surface morphologies of the PI films after metallization of Ni on PI. The time $(5,10,15 \mathrm{~min})$ shown in the top row is the immersion time in the $\mathrm{KOH}$ solution. 


\subsection{Cross-Sectional Characterization of Metallized PI Film}

To gain a better insight of Ni metallization on PI, the Ni-metallized PI film was cross-sectioned using FIB and the exposed Ni/PI interface was examined using TEM. As shown in Figure 4a, an electroless Ni layer with a thickness of $235 \mathrm{~nm}$ was formed on PI, where the $\mathrm{KOH}$ concentration used for base treatment was $0.5 \mathrm{M}$. A vague layer with a thickness of $30 \mathrm{~nm}$ was observed at the interface between electroless Ni and PI as shown in Figure 4b. This interfacial layer had a granular appearance which was considered to be composed of catalytic Ni nanoparticles resulting from the reduction reaction. The elemental mapping results (Figure $4 \mathrm{c}, \mathrm{d}$ ) showed that the electroless layer contained mostly Ni, with a small amount of P uniformly distributed in the electroless layer. P originated from the reducing agent (sodium hypophosphite) added in the commercial plating solution [36]. Figure 5 shows the cross-sectional TEM images of the Ni-metallized PI film with a KOH concentration increased to 5.0 M. An electroless Ni layer with a thickness of $200 \mathrm{~nm}$ was also formed; however, a specular interfacial layer was observed between electroless Ni and PI. This interfacial layer was approximately $1600 \mathrm{~nm}$ and several granular nanoparticles were embedded inside (Figure 5a). These granular nanoparticles were also Ni (identified by the elemental mapping analysis (Figure 5b)) and their sizes ranged from $40 \mathrm{~nm}$ to $50 \mathrm{~nm}$ (Figure 5c,d). It is most likely that these granular Ni nanoparticles were also catalysts produced by the reduction reaction. However, these granular Ni nanoparticles failed to aggregate in a confined region as shown in Figure $4 b$, where the granular Ni nanoparticles aggregated in a $30 \mathrm{~nm}$ thick interfacial region. This indicates that the $\mathrm{KOH}$ concentration used for base treatment played an important role in the formation and distribution of reduced Ni nanoparticles.

To understand the influence of the base treatment, the PI film was cross-sectioned and examined after each step of the metallization process. First, a bare PI film was treated using $5.0 \mathrm{M} \mathrm{KOH}$ and its cross section was observed using TEM. As shown in Figure 6a, base treatment of $\mathrm{KOH}$ resulted in the formation of a PAA layer on the PI surface. The morphology of the PAA layer was slightly different to that of the bottom non-treated PI film. Figure $6 \mathrm{~b}$ shows the elemental mapping results of potassium. The distribution of the potassium ions in the PAA layer was observed and the distribution depth, that is, the thickness of the PAA layer, was about $2.6 \mu \mathrm{m}$. The distribution of potassium was also locally examined using EDX. The results showed that the content of potassium was 6.3 at $\%$ at the upmost sublayer (point 1) and decreased to 1.7 at $\%$ and 0 at \% at inner points 2 and 3, respectively. Figure 7 shows the line-scan result and potassium was detected at a depth length of $2500 \mathrm{~nm}$ on the PI surface which is consistent with the elemental mapping result in Figure 6b. Figure $6 c, d$ show the elemental mapping results of carbon and oxygen, respectively, and their distributions were approximately uniform in the entire PI film. 

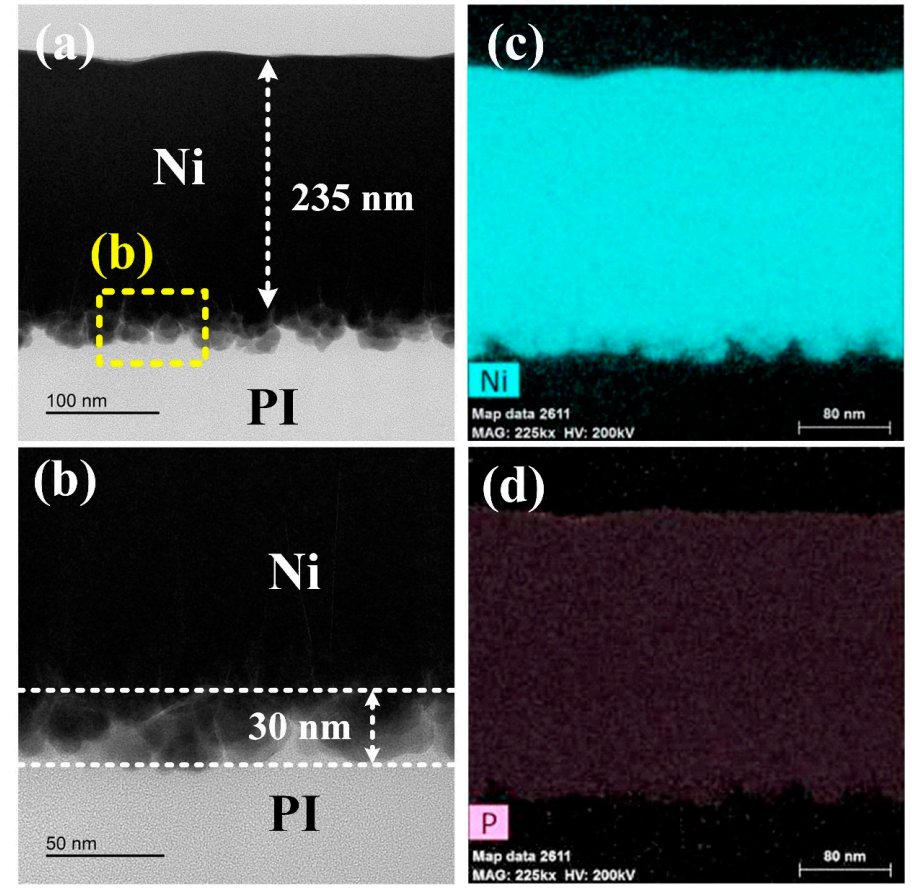

Figure 4. (a) Cross-sectional TEM image of the Ni-metallized PI film with the KOH concentration of base treatment of 0.5 M. (b) Enlarged image of the interfacial region marked in (a). (c,d) Elemental mapping results of $\mathrm{Ni}$ and $\mathrm{P}$ in the Ni-metallized PI film, respectively.
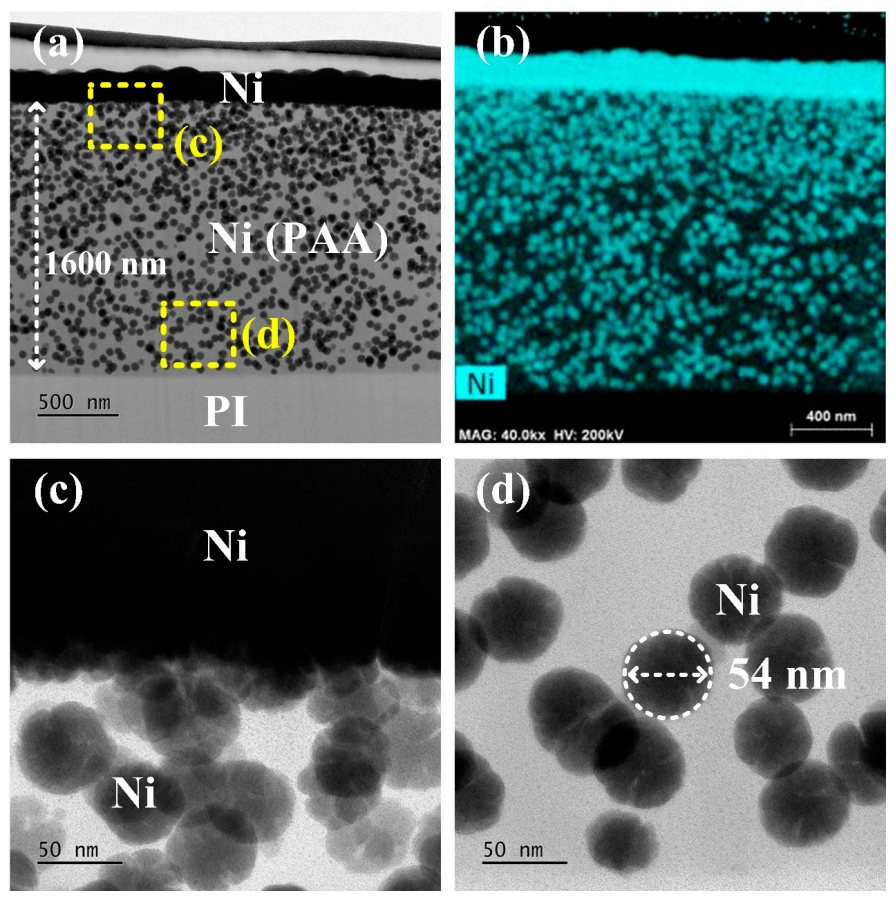

Figure 5. (a) Cross-sectional TEM image of the Ni-metallized PI film with a $\mathrm{KOH}$ base treatment concentration at 5.0 M. (b) Elemental mapping result of Ni in the Ni-metallized PI film. (c,d) Enlarged images of the interfacial and interior regions marked in (a). 

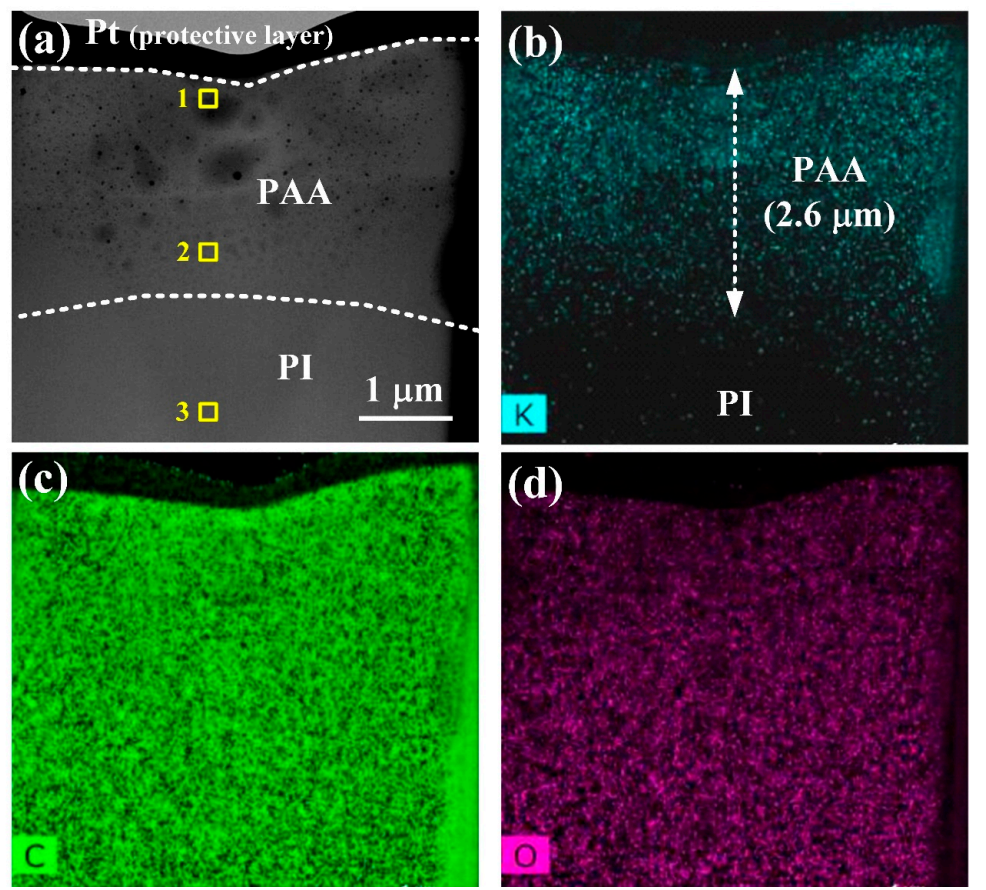

Figure 6. (a) Cross-sectional TEM image of the PI film after base treatment with a $\mathrm{KOH}$ concentration of $5.0 \mathrm{M}$. (b-d) Elemental mapping results of $\mathrm{K}, \mathrm{C}$, and $\mathrm{O}$ in the $\mathrm{KOH}$-treated PI film, respectively.

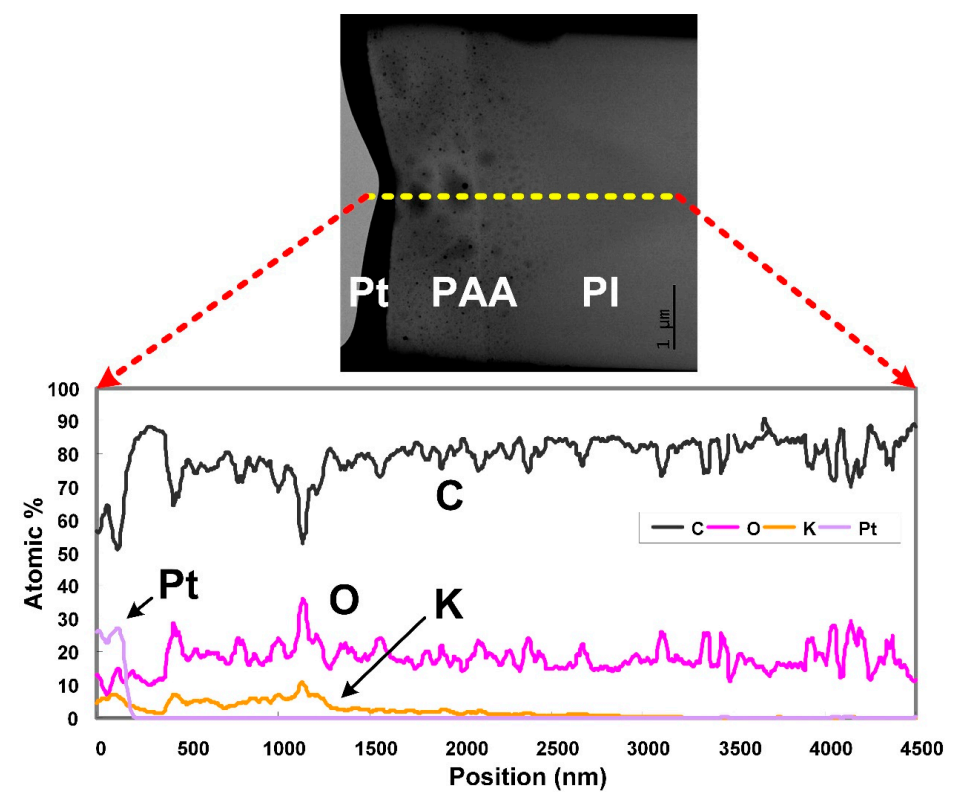

Figure 7. Elemental line-scan result across the surface sublayer of the PI film after base treatment of $\mathrm{KOH}$.

Figure 8 shows the cross-sectional TEM images of the PAA layer after Ni reduction. The thickness of the PAA layer was reduced to $714 \mathrm{~nm}$ as seen in Figure 8a, which was about a three-quarter reduction of the initial thickness $(2.6 \mu \mathrm{m}) . \mu \mathrm{A}$ magnified image of the PAA layer is shown in Figure $8 \mathrm{~b}$ where many Ni nanoparticles formed within the PAA layer, but some agglomerated on the film surface. The agglomerated Ni nanoparticles were distributed non-uniformly on the PI surface as shown in Figure 8c. It has been reported that the Ni nanoparticle film formed on PI was highly resistive due to a high sheet resistance $(109 \mathrm{M} \Omega / \gamma)$ [31]. The Ni nanoparticles within the PAA layer also distributed non-uniformly 
and their particle sizes were 7.5-19 $\mathrm{nm}$ as shown in Figure 8d. Figure 9 shows the line-scan result of the PAA layer after Ni reduction. No potassium signal was detected across the entire PAA layer, but the Ni signal was, indicating that the ion exchange reaction successfully replaced the $\mathrm{K}^{+}$ions by the $\mathrm{Ni}^{2+}$ ions in the PAA layer. In addition, as shown in Figure $6 \mathrm{~b}$, the initial PAA layer was $2.6 \mu \mathrm{m}$ thick with the distribution of $\mathrm{K}^{+}$ions. It was speculated that the PAA layer retained this thickness after the ion exchange reaction of Ni. However, the PAA thickness was significantly reduced to $714 \mathrm{~nm}$ after the reduction reaction above mentioned. This implies that the $\mathrm{Ni}^{2+}$ ions implanted in the PAA layer diffuse upwards to the PI surface to capture the electrons from the reductant $\left(\mathrm{NaBH}_{4}\right)$ and reduce the $\mathrm{Ni}$ atoms. Therefore, the PAA layer reduces in thickness due to the upward movement of $\mathrm{Ni}^{2+}$ ions.
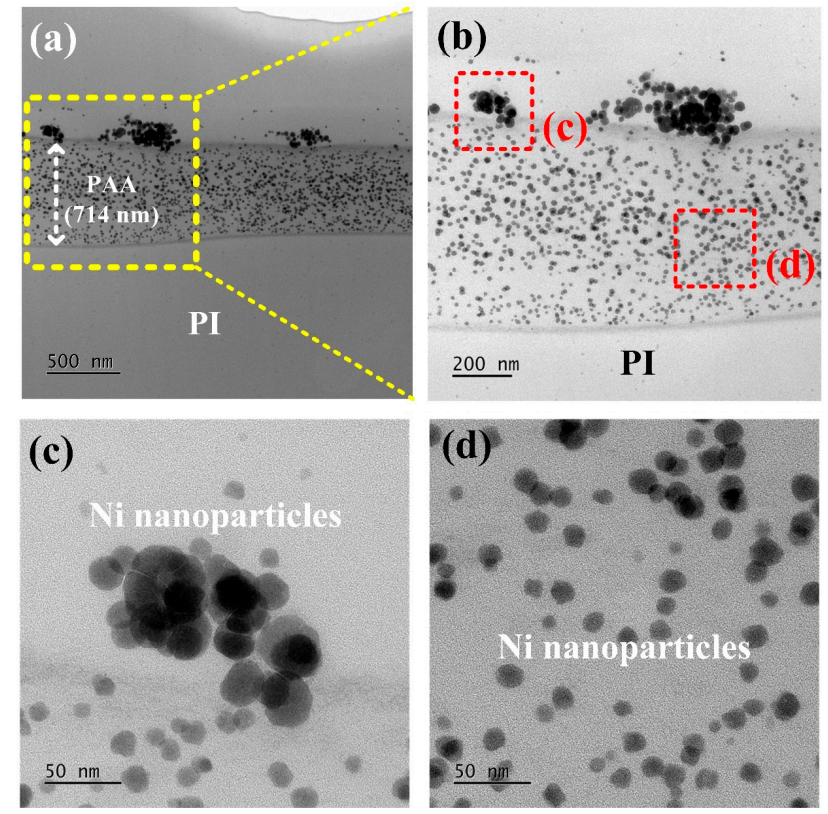

Figure 8. (a) Cross-sectional TEM image of the PI film after Ni reduction (The KOH concentration of base treatment is $5.0 \mathrm{M}$ ). (b) Enlarged image of the poly(amic acid) (PAA) layer marked in (a). (c,d) Enlarged images of the surface and interior regions of the PAA layer, respectively, marked in (b).

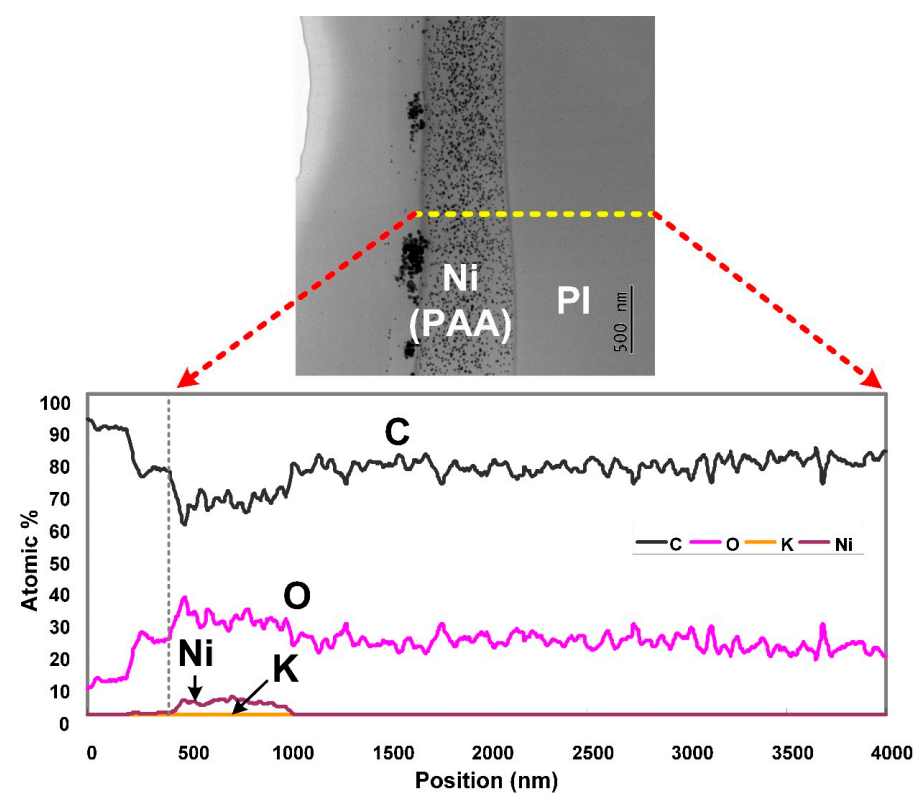

Figure 9. Elemental line-scan result across the surface sublayer of the PI film after Ni reduction. 
As noted in Figure 5a, the thickness of PAA was $1600 \mathrm{~nm}$ after the electroless deposition of $\mathrm{Ni}$ and was about two times thicker than that after Ni reduction $(714 \mathrm{~nm}$ ) (Figure 8a). This indicates that high-temperature electroless deposition of $\mathrm{Ni}\left(85^{\circ} \mathrm{C}\right)$ may drive the reduced $\mathrm{Ni}$ atoms to move deeper into the PI film. To verify the above inference, one PI sample (after the reduction reaction of $\mathrm{Ni}$ ) was placed into an oven at $85^{\circ} \mathrm{C}$ for $5 \mathrm{~min}$. It was found that the thickness of PAA increased to $1350 \mathrm{~nm}$ (Figure 10a), implying that the Ni atoms indeed diffuse inwardly. The root cause is still unclear, but may be related to the incomplete structure of the PAA layer. As above-mentioned, the initial PAA layer was $2.6 \mu \mathrm{m}$ thick after $\mathrm{KOH}$ treatment, which implies that the structure in the $2.6 \mu \mathrm{m}$ thick region was destroyed (the imide rings are opened.). Furthermore, the incomplete structure of the PAA layer makes the diffusion of $\mathrm{Ni}$ ions (or atoms) easier. In the reduction reaction, Ni ions diffuse upwards to the PI surface to capture the electrons to reduce the Ni atoms, so the thickness of the composite layer $(\mathrm{PAA}+\mathrm{Ni})$ reduces to $714 \mathrm{~nm}$. However, the residual PAA layer with a thickness of $1886 \mathrm{~nm}$ $(=2.6 \mu \mathrm{m}-714 \mathrm{~nm})$ may still possess an incomplete structure. Therefore, in the subsequent electroless deposition, the higher treatment temperature $\left(85^{\circ} \mathrm{C}\right)$ enabled the reduced $\mathrm{Ni}$ atoms to diffuse inwards, i.e., in the opposite direction to the PI surface. Therefore, the thickness of the composite layer (PAA + $\mathrm{Ni}$ ) increased to $1600 \mathrm{~nm}$. It was noted that the diffusion of the $\mathrm{Ni}^{2+}$ ions during the reduction reaction was directional in the direction of the PI surface due to the attraction of electrons from the reducing agents. Therefore, the thickness of the composite layer (PAA + Ni) reduced. In contrast, the reduced $\mathrm{Ni}$ atoms could diffuse upwards and inward due to a lack of specific attraction during the electroless deposition. Therefore, the composite layer (PAA $+\mathrm{Ni}$ ) became thicker due to the inward diffusion of the Ni atoms. A comparison of Figures $8 \mathrm{~d}$ and $10 \mathrm{~b}$ revealed that the Ni nanoparticles grew, but particle density decreased under high-temperature treatment. The average particle density of Ni in the composite layers (PAA $+\mathrm{Ni})$ was quantitatively estimated based on at least three areas $(500 \mathrm{~nm} \times 500$ $\mathrm{nm}$ ) and they were $700 \mu \mathrm{m}^{-2}$ and $44 \mu \mathrm{m}^{-2}$ in Figures 8 and 10, respectively. The reduction of particle density could be attributed to the particle agglomeration in order to reduce total surface energy. A comparison of Figures $5 \mathrm{~d}$ and $8 \mathrm{~d}$ also revealed that the growth of the Ni nanoparticles occurred and the particle density decreased from $700 \mu \mathrm{m}^{-2}$ to $324 \mu \mathrm{m}^{-2}$ during the electroless deposition of Ni. This is because that the reduced Ni nanoparticles in Figure $8 \mathrm{~d}$ had superior electro-catalytic activity, so the Ni ions and electrons from the plating solution diffused into the PAA layer and contributed to the growth of the Ni nanoparticles. On the other hand, the structure of the PAA layer may be destroyed and makes the diffusion of the Ni ions and electrons into the PAA layer easier.
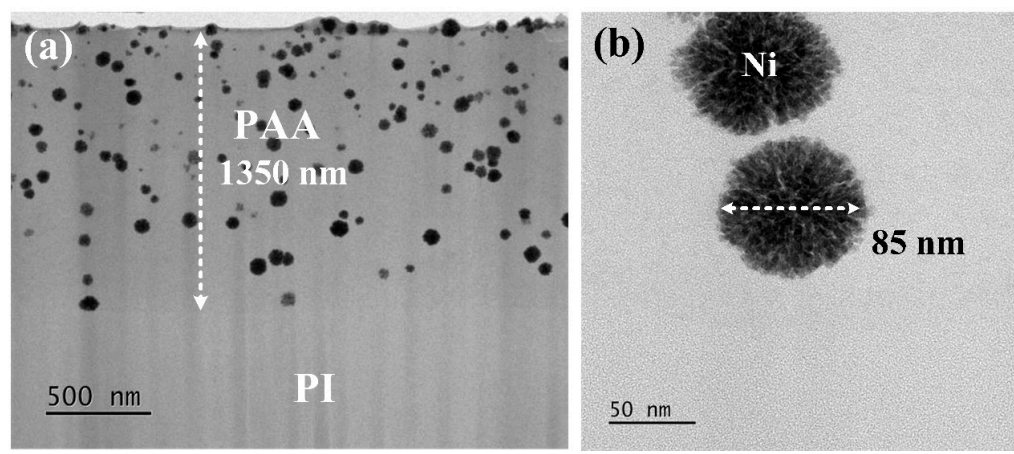

Figure 10. (a) Cross-sectional TEM images of the PI film after Ni reduction, followed by heat treatment in an oven at $85^{\circ} \mathrm{C}$ for $5 \mathrm{~min}$. (b) Enlarged image of the Ni nanoparticles embedded in the PAA layer.

\subsection{Pull-Off Examination of Metallized Layer on PI Film}

Figure 11 plots the peel strength of the electroless Ni layers on two modified PI films. On average, the electroless Ni layer on the PI film modified by $0.5 \mathrm{M} \mathrm{KOH}$ exhibited higher peel strength when compared with a $5.0 \mathrm{M} \mathrm{KOH}$-modified PI film. The best peel strength reached $0.7 \mathrm{Kgf}$ for the $0.5 \mathrm{M}$ KOH-modified PI film, which was about four times higher than that $(0.18 \mathrm{Kgf})$ of the $5.0 \mathrm{M}$ 
KOH-modified PI film. Fracture surface examination based on SEM observation showed that the fracture path was approximately along the Ni/PI interface. The higher peel strength of the $0.5 \mathrm{M}$ $\mathrm{KOH}$-modified sample was attributed to the formation of a dense and uniform Ni nanoparticle interlayer (Figure 4b) which effectively interlocked the electroless Ni layer and PI film. In contrast, the thick PAA interlayer with uneven distribution of Ni nanoparticles in the 5.0 M KOH-modified sample (Figure 5a) was unfavorable for metallic layer adhesion, thus the electroless Ni layer was easily peeled off with a lower strength.

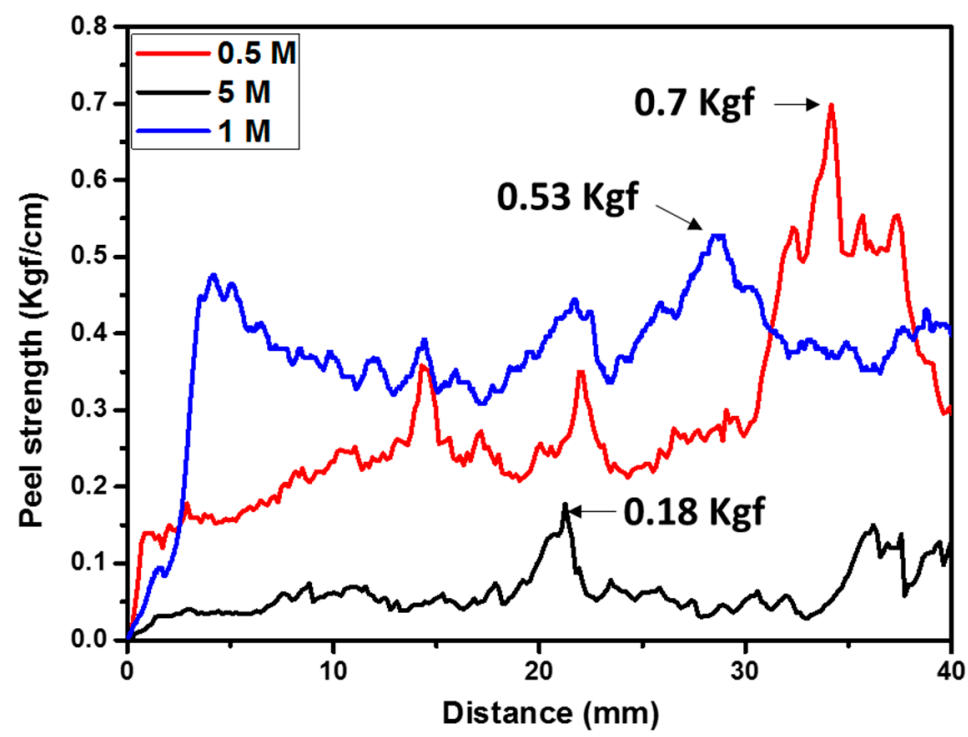

Figure 11. Peel strength of the electroless Ni layers on two PI films modified by $0.5 \mathrm{M}$ and $5.0 \mathrm{M} \mathrm{KOH}$.

\section{Conclusions}

The $\mathrm{KOH}$ concentration for the ring-opening reaction played a crucial role in the surface metallization of $\mathrm{Ni}$ on a PI film. At a lower concentration $(0.1 \mathrm{M})$, incomplete deposition of $\mathrm{Ni}$ with poor adhesion on PI was observed. When the $\mathrm{KOH}$ concentration was increased to $0.5 \mathrm{M}$ and higher, a uniform Ni layer was formed on the PI with full coverage. The optimal $\mathrm{KOH}$ concentration was $0.5 \mathrm{M}$ where a dense and uniform $\mathrm{Ni}$ nanoparticle interlayer formed as an effective interlock to improve the adhesion strength of the electroless Ni layer on PI. However, for a high concentration of $\mathrm{KOH}(5.0 \mathrm{M})$, a thick PAA interlayer with an uneven distribution of Ni nanoparticles formed at the electroless Ni/PI interface. This PAA composite interlayer appeared to be mechanically weak, and the electroless Ni layer displayed a lower peel strength as it could be peeled off from the PI film.

Acknowledgments: This work was supported by the Ministry of Science and Technology, Taiwan (MOST 104-2218-E-005-006).

Author Contributions: Ching-Hsuan Lin and Chih-Ming Chen conceived and designed the experiments. Pei-Yu Wu performed the experiments. Pei-Yu Wu and Chih-Ming Chen analyzed the date. Chih-Ming Chen wrote the manuscript and supervised the whole study. All authors reviewed the final paper.

Conflicts of Interest: The authors declare no conflict of interest.

\section{References}

1. Dow, W.P.; Liao, G.L.; Huang, S.E.; Chen, S.W. Modification of Cu nanoparticles with a disulfide for polyimide metallization. J. Mater. Chem. 2010, 20, 3600-3609. [CrossRef]

2. Park, S.C.; Min, K.J.; Lee, K.H.; Jeong, Y.; Park, Y.B. Effect of annealing on the interfacial adhesion energy between electroless-plated Ni and polyimide. Met. Mater. Int. 2011, 17, 111-115. [CrossRef]

3. Suh, S.W.; Kim, J.J.; Kim, S.H.; Park, B.K. Effect of PI film surface on printing of Pd(II) catalytic ink for electroless copper plating in the printed electronics. J. Ind. Eng. Chem. 2012, 18, 290-294. [CrossRef] 
4. Shen, F.Y.; Huang, S.E.; Dow, W.-P. Silver Metallization of Polyimide Surfaces Using Environmentally Friendly Reducing Agents. ECS Electrochem. Lett. 2013, 2, D45-D48. [CrossRef]

5. Giovangrandi, L.; Gilchrist, K.H.; Whittington, R.H.; Kovacs, G.T. Low-cost microelectrode array with integrated heater for extracellular recording of cardiomyocyte cultures using commercial flexible printed circuit technology. Sens. Actuators B Chem. 2006, 113, 545-554. [CrossRef]

6. Ng, J.H.G.; Desmulliez, M.P.Y.; Lamponi, M.; Moffat, B.G.; McCarthy, A.; Suyal, H.; Walker, A.C.; Prior, K.A.; Hand, D.P. A direct-writing approach to the micro-patterning of copper onto polyimide. Circuit World 2009, 35, 3-17. [CrossRef]

7. Fjelstad, J. Flexible circuit materials. Circuit World 2008, 34, 19-24. [CrossRef]

8. Yang, S.; Wu, D.; Qi, S.; Cui, G.; Jin, R.; Wu, Z. Fabrication of highly reflective and conductive double-surface-silvered layers embedded on polymeric films through all-wet process at room temperature. J. Phys. Chem. B 2009, 113, 9694-9701. [CrossRef] [PubMed]

9. Kim, H.J.; Park, Y.J.; Choi, J.H.; Han, H.S.; Hong, Y.T. Surface modification of polyimide film by coupling reaction for copper metallization. J. Ind. Eng. Chem. 2009, 15, 23-30. [CrossRef]

10. Akamatsu, K.; Ikeda, S.; Nawafune, H.; Deki, S. Surface modification-based synthesis and microstructural tuning of nanocomposite layers: Monodispersed copper nanoparticles in polyimide resins. Chem. Mater. 2003, 15, 2488-2491. [CrossRef]

11. Akamatsu, K.; Ikeda, S.; Nawafune, H. Site-selective direct silver metallization on surface-modified polyimide layers. Langmuir 2003, 19, 10366-10371. [CrossRef]

12. Ho, S.M.; Wanc, T.H.; Chen, H.L.; Chen, K.M.; Man, S.M.; Hung, A. Metallization of polyimide film by wet process. J. Appl. Polym. Sci. 1994, 51, 1373-1380. [CrossRef]

13. Akamatsu, K.; Ikeda, S.; Nawafune, H.; Yanagimoto, H. Direct patterning of copper on polyimide using ion exchangeable surface templates generated by site-selective surface modification. J. Am. Chem. Soc. 2004, 126, 10822-10823. [CrossRef] [PubMed]

14. Liu, W.; Xu, Z.; Wu, D.; Wu, Z.; Hu, T.S. Systematic synthesis of polyimide@ inorganics core-shell microspheres via ion-exchange and interfacial reaction. Mater. Lett. 2016, 177, 30-33. [CrossRef]

15. Ran, J.; Zhang, J.; Yao, W.; Wei, Y. Properties of $\mathrm{Cu}$ film and Ti/Cu film on polyimide prepared by ion beam techniques. Appl. Surf. Sci. 2010, 256, 7010-7017. [CrossRef]

16. Stephans, L.E.; Myles, A.; Thomas, R.R. Kinetics of alkaline hydrolysis of a polyimide surface. Langmuir 2000, 16, 4706-4710. [CrossRef]

17. Cho, S.-J.; Shrestha, S.P.; Boo, J.-H. Surface treatment for Cu metallization on polyimide film by atmospheric pressure dielectric barrier discharge plasma system. Curr. Appl. Phys. 2011, 11, S135-S139. [CrossRef]

18. Wu, H.; Susanto, A.; Lian, K. Thin and flexible Ni-P based current collectors developed by electroless deposition for energy storage devices. Appl. Surf. Sci. 2017, 394, 63-69. [CrossRef]

19. Liao, B.; Wu, X.Y.; Zhang, X.; Liang, H.; Zhang, H.-X. The study of polyimide modified by Ni plasma and its adhesion to Cu films. Nucl. Instrum. Methods Phys. Res. Sec. B 2013, 307, 580-585. [CrossRef]

20. Papadopoulou, E.L.; Morselli, D.; Prato, M.; Barcellona, A.; Athanassiou, A.; Bayer, I.S. An efficient pure polyimide ammonia sensor. J. Mater. Chem. C 2016, 4, 7790-7797. [CrossRef]

21. Putz, B.; Schoeppner, R.L.; Glushko, O.; Bahr, D.F.; Cordill, M.J. Improved electro-mechanical performance of gold films on polyimide without adhesion layers. Scr. Mater. 2015, 102, 23-26. [CrossRef] [PubMed]

22. Woo, T.G.; Park, I.S.; Jung, K.H.; Jeon, W.Y.; Seol, K.W. Effect of RF sputtering power on the adhesion of Ni thin film to polyimide. Electron. Mater. Lett. 2011, 7, 353-358. [CrossRef]

23. Kotnur, V.; Tichelaar, F.; Janssen, G. Sputter deposited Ni-Ti thin films on polyimide substrate. Surf. Coat. Technol. 2013, 222, 44-47. [CrossRef]

24. Matsubara, H.; Yonekawa, T.; Ishino, Y.; Saito, N.; Nishiyama, H.; Inoue, Y. The observation of the nucleation and growth of electrolessly plated nickel deposited from different bath $\mathrm{pH}$ by TEM and QCM method. Electrochim. Acta 2006, 52, 402-407. [CrossRef]

25. Mu, S.; Wu, D.; Wang, Y.; Wu, Z.; Yang, X.; Yang, W. Fabrication of nickel oxide nanocomposite layer on a flexible polyimide substrate via ion exchange technique. ACS Appl. Mater. Interfaces 2009, 2, 111-118. [CrossRef] [PubMed]

26. Thomas, R.R. Wetting kinetics of modified polyimide surfaces: Interactions with polar solvents. J. Colloid Interface Sci. 2004, 279, 515-522. [CrossRef] [PubMed] 
27. Li, Y.; Lu, Q.; Qian, X.; Zhu, Z.; Yin, J. Preparation of surface bound silver nanoparticles on polyimide by surface modification method and its application on electroless metal deposition. Appl. Surf. Sci. 2004, 233, 299-306. [CrossRef]

28. Ikeda, S.; Yanagimoto, H.; Akamatsu, K.; Nawafune, H. Copper/Polyimide Heterojunctions: Controlling Interfacial Structures Through an Additive-Based, All-Wet Chemical Process Using Ion-Doped Precursors. Adv. Funct. Mater. 2007, 17, 889-897. [CrossRef]

29. Akamatsu, K.; Nakahashi, K.; Ikeda, S.; Nawafune, H. Fabrication and structural characterization of nanocomposites consisting of Ni nanoparticles dispersed in polyimide films. Eur. Phys. J. D 2003, 24, 377-380. [CrossRef]

30. Hsiao, Y.-S.; Whang, W.-T.; Wu, S.-C.; Chuang, K.-R. Chemical formation of palladium-free surface-nickelized polyimide film for flexible electronics. Thin Solid Films 2008, 516, 4258-4266. [CrossRef]

31. Cherng, S.-J.; Chen, C.-M.; Dow, W.-P.; Lin, C.-H.; Chen, S.-W. Chemical deposition of Ni/Pt Bi-layer on polyimide film as flexible counterelectrodes for dye-sensitized solar cells. Electrochem. Solid State Lett. 2011, 14, P13-P15. [CrossRef]

32. Akamatsu, K.; Shinkai, H.; Ikeda, S.; Adachi, S.; Nawafune, H.; Tomita, S. Controlling interparticle spacing among metal nanoparticles through metal-catalyzed decomposition of surrounding polymer matrix. J. Am. Chem. Soc. 2005, 127, 7980-7981. [CrossRef] [PubMed]

33. Chen, D.; Lu, Q.; Zhao, Y. Laser-induced site-selective silver seeding on polyimide for electroless copper plating. Appl. Surf. Sci. 2006, 253, 1573-1580. [CrossRef]

34. Ikeda, S.; Akamatsu, K.; Nawafune, H.; Nishino, T.; Deki, S. Formation and growth of copper nanoparticles from ion-doped precursor polyimide layers. J. Phys. Chem. B 2004, 108, 15599-15607. [CrossRef]

35. Li, L.; Ma, Y.; Gao, G.; Wang, H.; Yang, X.; Xie, J.; Wang, W. Pretreatment and deposition process of electroless Ni plating on polyimide film for electronic field applications. Colloids Surf. A 2015, 477, 42-48. [CrossRef]

36. Lai, K.C.; Wu, P.Y.; Chen, C.M.; Wei, T.C.; Wu, C.H.; Feng, S.P. Interfacial characterizations of a nickel-phosphorus layer electrolessly deposited on a silane compound-modified silicon wafer under thermal annealing. J. Electron. Mater. 2016, 45, 4813-4822. [CrossRef]

(C) 2017 by the authors. Licensee MDPI, Basel, Switzerland. This article is an open access article distributed under the terms and conditions of the Creative Commons Attribution (CC BY) license (http:/ / creativecommons.org/licenses/by/4.0/). 